\title{
Linguística aplicada e visão de linguagem: por uma INdisciplinaridade radical
}

\section{Applied linguistics and language: towards radical indisciplinarity}

\author{
Branca Falabella Fabrício \\ Universidade Federal do Rio de Janeiro \\ Rio de Janeiro, Rio de Janeiro / Brasil
}

\begin{abstract}
RESUMO: Este artigo tem por objetivo propor uma visão de linguística aplicada e de linguagem comprometidas como uma INdisciplinaridade radical. No desenvolvimento dessa proposta, convoca autores/as de diferentes áreas do conhecimento para refletir tanto sobre processos históricos de territorialização forjados no chamado período moderno quanto possibilidades de transgressão. $\mathrm{O}$ argumento central é que um pensamento de fronteira implica uma série de desafios, sobretudo "desacostumar" e "despraticar" normas familiares.
\end{abstract}

PALAVRAS-CHAVE: Linguística aplicada; linguagem; indisciplinaridade; pensamento de fronteira; transgressão.

\begin{abstract}
This article puts forward a view of Applied Linguistics and language committed to radical INdisciplinarity. To achieve this goal it congregates authors from different fields to reflect both upon historical processes of territorialization forged in the so-called Modernity and possibilities of transgression. The central argument is that border thinking involves many challenges, especially reexamining familiar norms and making them strange.
\end{abstract}

KEYWORDS: Applied Linguistics; language; indisciplinarity; border thinking; transgression.

\section{Introdução}

Uso a palavra para compor meus silêncios.

Não gosto das palavras fatigadas de informar.

(“O apanhador de desperdícios”, Manoel de Barros)

Este ensaio visa a refletir sobre alguns desafios que as ideias de trânsito e transgressão implicadas na perspectiva da "INdisciplina" apresentam para a linguística aplicada contemporânea e para os modos de produção

$\overline{\text { * branca.falabella@pq.cnpq.br }}$ 
de conhecimento em geral. O texto está organizado em quatro partes. A primeira busca apoio em dois autores estranhos à linguística aplicada, na busca de algumas metáforas, termos e vocabulário que permitam a exploração de noções como fronteira e violação. A segunda dá continuidade a essa reflexão inicial e elege autores(as) e conceitos de referência no campo dos estudos da linguagem que movimentam a chamada episteme colonial. A terceira vislumbra questões e desafios que a perspectiva esboçada coloca para a área em questão quando esta se desloca para além de perímetros conhecidos. Na sequência, um último bloco de ponderações aponta para possíveis desdobramentos da discussão encaminhada em nossas ações teórico-metodológico-analíticas, enfatizando o "desaprender" e "despraticar" normas como estratégias centrais na reconstrução de conhecimento. O elo entre cada parte é tecido por conjuntos de perguntas que costuram a perspectiva projetada.

\section{Sobre saberes e fronteiras}

O percurso aqui delineado foi traçado sob o impacto da leitura de duas obras que não são da área das humanidades, mas que, ao problematizarem as fronteiras que ainda insistem em separar os campos de conhecimento, operam segundo uma abordagem INdisciplinar que me levou a convocá-las ao diálogo.

A primeira delas é Confluências entre magia, filosofia, ciência e arte: a ontologia onírica, de Nelson Job (2013a). O autor - que é doutor em História das Ciências, das Técnicas e Epistemologia, e formado em Psicologia Clínica - advoga uma transdisciplinaridade radical em favor do que denominou manifesto Transaberes (2013b):

Não existe saber da ordem do "multi" ou "inter", o saber sempre foi trans, atravessamento, aliança da intuição com a vida. Nem uma pura ontologia, muito menos uma epistemologia, mas uma epistemontologia, visto que o saber não opera por dualidades, mas por composição: não existe isolamento no saber, mas apenas relações de relações [...] Pois evidencia-se que todo saber é transaber, um suposto saber nunca se isola, pois é da prática da sabedoria relacionar.

O manifesto e o livro exploram as relações históricas e conceituais entre o hermetismo, a filosofia da diferença deleuziana e a física moderna, colocando em diálogo discursos da teoria quântica, teoria do caos, magia, taoísmo, budismo, filosofia e arte. A conversa proposta não é mera justaposição de campos do saber, mas cópula - é colocar ideias “copulando 
com conceitos nunca antes articulados" (JOB, 2010) entre si como forma de movimentar-se além das fronteiras, em direção ao novo. Nesse caminho rumo ao desconhecido ou ao não ainda, enfrentamos nosso maior inimigo: os clichês. Sim, pois o clichê, segundo o autor, perpassa todos os âmbitos de nossas vidas - "dos mais ínfimos, aos mais óbvios". "Pensamos, amamos, apreciamos 'arte', nos drogamos, rezamos etc. com clichê[s]. O clichê se tornou a mais terrível ubiquidade de nossa era" (JOB, 2010).

A segunda obra, A lógica da diferença (2001), de Luiz Sérgio Coelho Sampaio, ex-engenheiro da Empresa Brasileira de Telecomunicações (Embratel) já falecido, se debruça sobre a história do pensamento lógico ocidental. Autodidata e fora dos corredores da academia, Sampaio rastreou séculos de tradição filosófico-científica, organizando e sistematizando, em notas e em diversos compêndios, nossos modos de pensamento que operariam segundo um esquema universal de natureza lógica. Os textos produzidos eram datilografados, xerocados e distribuídos entre seus colegas de trabalho, e, até onde tenho notícia, encontram-se guardados na biblioteca da Embratel. O livro é sua única publicação em formato acadêmico. O que nele me atraiu não foram as inúmeras fórmulas, equações e axiomas, das quais faço pouco ou nenhum juízo, por total incompetência minha, faço questão de afirmar. O que me surpreendeu foi a excepcional capacidade de síntese na redução do pensamento a um modelo que tem por chave mestra dois elementos lógicos de base - identidade (I) e diferença (D) e dois outros deles derivados - dialética $(\mathrm{I} / \mathrm{D})$ e dupla diferença $\left(\mathrm{D}^{2}\right)$. A desconcertante simplificação, redutora de parte expressiva da história da humanidade, é formalizada na Figura 1.

FIGURA 1 - As quatro lógicas de base

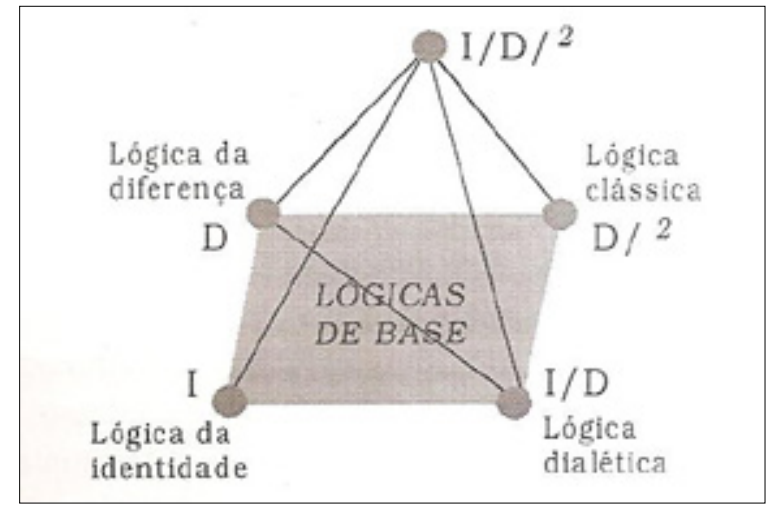

Fonte: Sampaio (2001, p. 62) 
Com muita modéstia, apresento uma explicação, reconstruindo a forma como projetei sentido sobre o mosaico de lógicas do engenheiro. Segundo ele, a tradição sempre lidou com três lógicas: a lógica da identidade (isto é, a lógica da consciência, do sujeito e do ser pensante cartesiano); a lógica clássica aristotélica do método científico; e a lógica dialética (a da História, do movimento e da materialidade). O avanço do esquema de Sampaio é, segundo ele próprio, ampliar de três para quatro o número de lógicas, retirando "o papel paradigmático indevidamente atribuído à lógica clássica, passando-o, como seria bem mais razoável, para as lógicas fundamentais, da identidade e diferença" (2001, p. 63). A essas lógicas de base, o autor acrescenta uma quinta, a lógica hiperdialética $\left(\mathrm{I} / \mathrm{D}^{2}\right)$ que, condensando todas as outras, seria a lógica do discurso e das subjetividades em sua plenitude. Os descentramentos operados por essa proposta, a princípio “quadripolar" e, depois, "quinquitária”, não são banais e merecem um olhar um pouco mais atento. Ocupo-me deles brevemente.

Ao destronar a lógica clássica $\left(\mathrm{D}^{2}\right)$ de seu protagonismo e subordinála à lógica da simples diferença (D), o autor produz uma distinção bastante significativa. Vamos a ela. A lógica D - isto é, nossa capacidade de atentar, discriminar, diferenciar, segregar, recortar e marcar - seria o exercício, ou a ação, daquilo que entendemos por cogito (lógica I) debruçando-se sobre a res extensa - concebida como um domínio amorfo, impreciso, indefinido e indeterminado. Ao abismar-se sobre a indiferença (isto é, sobre o nada), a consciência produziria duas formas de diferenciação - ou recorte/ negação na terminologia de Sampaio (2001, p. 43) - conforme ilustrado na Figura 2, em que 1, 0 e -1 correspondem respectivamente aos valores verdadeiro, indeterminado e falso, e D, à operação da negação:

FIGURA 2 - Lógica D - negações/ recortes

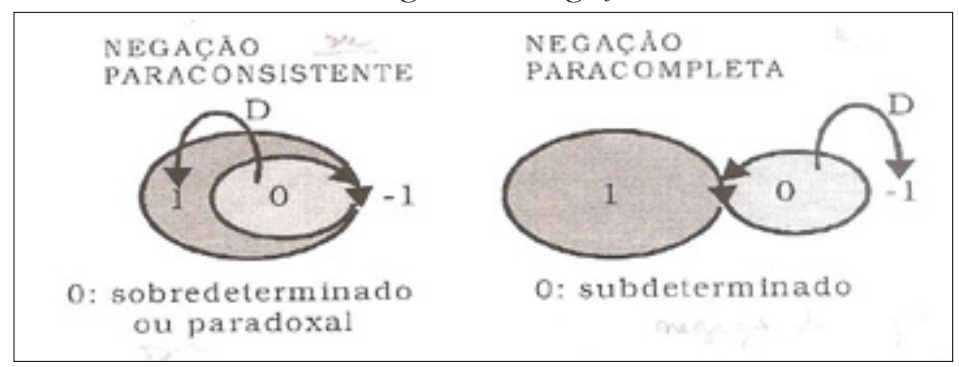

Fonte: Sampaio (2001, p. 43) 
No primeiro movimento lógico, o indeterminado, ou "nada", ficaria dentro do recorte produzido, que passa a ser tomado como "o real" e "verdadeiro". A imprecisão (0) capturada, contida e imobilizada é sobredeterminada pelo binômio verdadeiro/falso (1/-1), excluindo o falso da operação do pensamento. Essa articulação é conhecida pelo princípio do terceiro excluído no sistema clássico, para o qual existiriam apenas ser e não ser, sem chances para uma terceira possibilidade. Perguntas dilemáticas, como a que assombrou nosso querido bardo, "to be or not to be", ocupariam um lugar desprezado na cultura ocidental, caso não rompessem com a indecidibilidade, eliminando uma das proposições. Aqui, a projeção é de um solo seguro, em que reinam os estereótipos, clichês, binarismos, certezas, essencialismos e sentidos universais. Esse seria o mecanismo da lógica $\mathrm{D}^{2}-$ a do duplo movimento da diferença sobre a diferença: não apenas discriminação, mas também essencialização. Produtora de identidades por excelência, ela faz da identidade um efeito, produzido por uma operação sobre a diferença (D).

No segundo movimento, contrariamente, o "nada" ficaria fora do recorte, ocupando um espaço de copertinência. Ao admitir ser e não ser ao mesmo tempo - ou seja, uma afirmação e sua negação simultaneamente - ele abre espaço para uma terceira possibilidade de sentido (o falso), de forma que sendo sua negação subdeterminada, pode gerar infinitamente novas negações, isto é, novos pensamentos. Nem verdadeiros nem falsos; contínuos "to be and not to be", acrescidos de todas as contradições e paradoxos que os modos culturais ditos racionais têm por hábito desacreditar. Essa seria a lógica dos sonhos, dos lapsos, dos desejos, da imaginação criativa e dos signos, em suas pluralidades, ambiguidades, acasos, instabilidades, indefinições, vazamentos e deslizes - sempre vagando por superfícies tomadas como móveis. Estas últimas, como suporte de formas de conhecer, não teriam lugar no chamado método científico, porque a ancoragem, sistematização, padronização, previsibilidade e reprodutibilidade a ele tão caras são nômades e refratárias. 
Essas características podem ser assim resumidas na Figura 3:

FIGURA 3 - Operações das lógicas D e D² sobre o "nada"

\begin{tabular}{|l|l|}
\hline Simples diferença (D) & \multicolumn{1}{|c|}{ Dupla diferença $\left(D^{2}\right)$} \\
\hline imprecisão & objetividade \\
sonho & busca da verdade \\
desejos & método científico - sistematização \\
ambiguidade & técnica \\
pluralidade & binarismos (verdadeiro ou falso) \\
deslizamento & previsibilidade \\
vazamento & controle \\
nomadismo & territorialização \\
signos & epistemologia \\
contradição, paradoxo & não contradição \\
terceiro excluido: SIM & terceiro excluído: NÃo \\
"to be AND not to be" & "to be oR not to be" \\
\hline
\end{tabular}

Além da discriminação de diferença (D) e dupla diferença $\mathrm{D} / \mathrm{D}\left(\mathrm{D}^{2}\right)$, e o destronamento da segunda de sua centralidade no campo do pensamento, outro descentramento que julgo ser pertinente explorar é a projeção de uma quinta lógica, síntese de todas as outras, a hiperdialética $\left(\mathrm{I} / \mathrm{D}^{2}\right)$. Segundo Sampaio (2001), ela caracterizaria, com exclusividade, o ser humano, articulando os níveis simbólico, convencional e subjetivo. Esses seriam inseparáveis, não havendo precedência de um sobre os outros (SAMPAIO, 2001, p. 66): ao se eliminar um deles da base lógica, todo o edifício teóricoepistemológico desmoronaria. Seria a totalidade da construção, sempre em estado operatório, isto é, em movimento (ou em trabalho), que nos identificaria como seres do discurso. Primeiramente, é preciso haver consciência: de si, de autoidentidade (I); e do "outro", uma capacidade lógico-diferencial geral (D). Essas duas ações fundamentais se combinam e se dobram sobre si mesmas, produzindo duas derivações: a diferença da diferença (D/D) - atividade reflexiva complexa - e a síntese relacional de identidade e diferença (I/D) que instaura nosso sentido de historicidade.

Seria com base no diálogo incessante entre essas quatro lógicas, compreendidas como práticas de espacialidade, isto é, de estipulação de fronteiras $\left(\mathrm{I}\right.$ e $\left.\mathrm{D}^{2}\right)$ e temporalidade $(\mathrm{D}$ e I/D) que produziríamos nossos jogos de ser-dizer-fazer, significar, conhecer e pensar, os quais, segundo 
Sampaio (2001), seriam jogos discursivos, articulados em processos histórico-culturais, que se desenvolvem sobre territórios amorfos.

Apesar do esboço desse panorama potencialmente criativo, Sampaio (2001) aponta para a soberania de $\mathrm{D}^{2}$, tomada como hegemônica na tradição científica ocidental em relação às outras lógicas que acabaram por sucumbir a seu imobilismo. Também associa esse império de $\mathrm{D}^{2}$ a uma marca da modernidade e do capitalismo de produção, cuja afirmação se calcou no "recalque" e "domesticação" das outras lógicas, resultando "na história degenerada, pré-calculada, a que chamamos progresso" (SAMPAIO, 2001, p. 148). Da mesma forma e cada vez mais tecnológico, o capitalismo contemporâneo parece ser movido quase que exclusivamente pela lógica da dupla diferença, produtora de uma poderosa epistemologia das certezas. Segundo o autor, nossa herança moderna segue intacta: "Por que não reagimos?!” (SAMPAIO, 2001, p. 149), pergunta ele estupefato.

Em face dessas ponderações e retomando as especulações de Job e sua defesa de uma transdisciplinaridade radical, alguns desafios logo se projetam em relação à proposta de movimentação para além das fronteiras no campo da produção de conhecimento:

- Como enfrentar as fronteiras de modos de pensar "colonizados" pela lógica da dupla diferença $\left(\mathrm{D}^{2}\right)$ ?

- Como produzir "epistemontologias" segundo um jogo hiperdialético?

- Como atualizar academicamente práticas transaberes?

- Como movimentar a engrenagem moderna?

A meu ver, a resposta às três primeiras indagações depende do enfrentamento da última.

\section{A episteme colonial em trânsito}

Job e Sampaio não estão sozinhos em suas elucubrações, ou fabulações oníricas. Vários autores, na linguística aplicada e nas humanidades em geral, já vêm produzindo uma crítica consistente ao que pode ser chamado de episteme colonial. Vimos operando vários trânsitos, como o da disciplina, interdisciplina, multidisciplina, transdisciplina até a INdisciplina. Obras como Vigiar e punir (FOUCAULT, 1996), Linguística aplicada e transdisciplinaridade (SIGNORINI; CAVALCANTI, 1998), Identidades: recortes multi e interdisciplinares (MOITA LOPES; BASTOS, 2002) e Por uma Linguística aplicada indisciplinar (MOITA LOPES, 2006) são importantes companhias nesse percurso. 
Há também uma longa trajetória de problematização de abordagens essencializadas da relação identidade/diferença, que algumas obras seminais nos ajudam a questionar: Diferença e repetição (DELEUZE, 2009), A identidade cultural na pós-modernidade (HALL, 1992), Lingua(gem) e identidade (SIGNORINI, 1998), Identidades fragmentadas (MOITA LOPES, 2002), Identidade (BAUMAN, 2005), Para além da identidade: fuxos, movimentos e trânsitos (MOITA LOPES; BASTOS, 2010).

Já outro grupo de autora/es vem se aproximando de imagens, metáforas e conceitos da física quântica e teoria do caos para pensar a complexidade envolvida nas práticas de produção de sentido. Publicações como Ethnography, superdiversity, and linguistic landscapes: chronicals of complexity (BLOMMAERT, 2013), Sistemas adaptativos complexos: lingua(gem) e aprendizagem (PAIVA; NASCIMENTO, 2009) e Fractals and fragmented identities in language acquisition (SADE, 2009) também se aventuram a borrar fronteiras entre saberes.

Entretanto, como bem nos lembra Joana Plaza Pinto1, "qualquer conceito ou teoria a princípio transgressor pode facilmente ser lido e operacionalizado segundo um quadro moderno", apagando, encapsulando, homogeneizando e unificando as diferenças de forma totalitária. Isso porque as fronteiras, físicas ou imaginárias, que erguemos ao longo dos séculos, constituintes da episteme ocidental, são insidiosas e costumam retornar nas nossas ações mais ordinárias, acadêmicas ou não.

Alguns exemplos corriqueiros mostram efeitos da operação demarcadora de $\mathrm{D}^{2}$ (Figuras 4, 5, 6).

FIGURA 4 - Efeitos de D²: Charge de Simon Taylor publicada em 2008

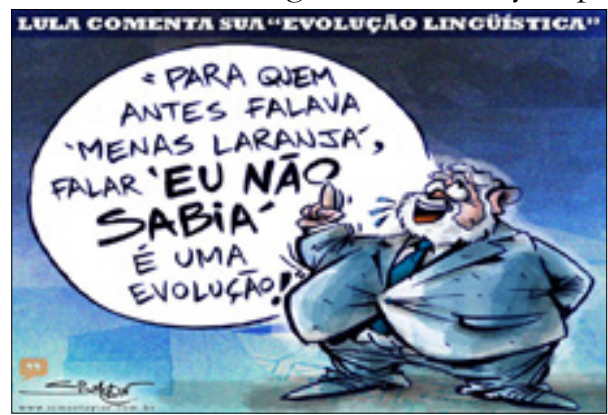

Fonte: http://preconceitolinguistico-gge.blogspot.com.br

\footnotetext{
${ }^{1}$ Notas realizadas durante apresentação de Joana Pinto na Escola de Altos Estudos, em 2015, em um curso desenvolvido com parceria entre Universidade Estadual de Campinas (Unicamp), Universidade Federal do Rio de Janeiro (UFRJ), Universidade Federal do Estado do Rio de Janeiro (Unirio), Universidade Federal de Goiás (UFG), entre outras instituições.
} 
FIGURA 5-Efeitos de $\mathrm{D}^{2}$ : mensagens em plataformas digitais e sites de relacionamento

Nordestino não é gente, faça um favor a SP, mate um nordestino afogado.

(Mensagem postada no Twitter em 2010)

Marco Feliciano aprova projeto
para cura gay
(Manchete no jornal Extra,
junho de 2013, reproduzida em
diferentes blogs)

Bia: Nossa que coisa mais ridícula, a mulher larga o marido pra ficar com a outra mulher e ainda quer que o filho pequeno aceite essa relação $[\ldots]$

Raúl: Definição de família. ("Homem e Mulher e Filhos"). O resto é gambiarra.

(Extra Online - comentários sobre a novela "Em família", 2013)

Me perdoem se for preconceito, mas essas médicas cubanas têm uma cara de empregada doméstica. Será que são médicas mesmo???? Afe, que terrível. Médico, geralmente, tem postura, tem cara de médico, se impõe através da aparência... Coitada de nossa população.

(post feito por uma jornalista do Rio Grande do Norte nas redes sociais, em 2013)

A breve trajetória compreendida entre a charge irônica e crítica ao expresidente Lula e sua forma de comunicação e os posts contra nordestinos e médicas cubanas nas redes sociais - passando por comentários feitos no site de um jornal on-line sobre o conceito de família e pela manchete sobre a cura de "espécies desviantes" (FOUCAULT, 1988) - compõe um roteiro ilustrativo de recorrentes efeitos de $\mathrm{D}^{2}$. A produção de fronteiras normativas 
em relação a línguas, gêneros, sexualidades, raças e classes sociais, bem como às práticas de governo e exclusão que essas barreiras ensejam são nossas velhas conhecidas. Por isso, não podemos ir além delas ou transgredi-las, sem nos ocupar de uma reflexão crítica radical da modernidade e das crenças por ela forjadas na sustentação do ideal herderiano "uma nação, um povo, uma língua". Crenças arraigadas sobre monolinguismo, pureza linguística, limites territoriais precisos, comunidades coesas, sujeitos soberanos e corporeidades idealizadas precisam ser revisitadas sob o risco de, se não o fizermos, não conseguirmos dar um passo à frente dos limites já demarcados.

Nessa empreitada, julgo que podemos conversar detidamente com a literatura que se encontra disponível. Cito algumas reflexões que, ao suspeitarem de categorizações modernistas, auxiliam o estranhamento de uma série de fronteiras:

a) entre territórios, comunidades e culturas, como: Modernity at large: cultural dimensions of globalization (APPADURAI, 1996); O local da cultura (BHABHA, 1998); e Local histories/global designs: coloniality, subaltern knowledges, and border thinking (MIGNOLO, 2000);

b) entre línguas, como: Linguistic utopias (PRATT, 1987); Language ideologies: practice and theory (SCHIEFFELIN; WOOLARD; KROSKRITY, 1998); Voices of modernity: language ideologies and the politics of inequality (BAUMAN; BRIGGS, 2003); Regimes of language: ideologies, polities and identities (KROSKRITY, 2000); A linguistica que nos far falbar (SILVA; RAJAGOPALAN, 2004); Disinventing and reconstituting languages (MAKONI; PENNYCOOK, 2006); e Global Portuguese: linguistic ideologies in late modernity (MOITA LOPES, 2015);

c) entre sujeitos e corpos (gênero, sexualidade, raça, classe, idade), como: Gender trouble: feminism and the subversion of identity (BUTLER, 1990); Sex in public (BERLANT; WARNER, 2005); e Manifesto Contrassexual: práticas subversivas de identidade sexual (PRECIADO, 2014).

Esse conjunto de narrativas nos auxilia a entender como I, D e I/D, sob a égide de $\mathrm{D}^{2}$, se articularam na formação dos Estadosnação e no estabelecimento do capitalismo e do modus vivendi burguês, formando uma rede semântica valorativa, de forte encadeamento lógico, que agregou uma série de sentidos à ideia de cultura, cidadania e identidade 
nacionais. Os corpos, a sexualidade, o sexo, a família e os espaços públicos e privados foram sanitarizados, purificados e capturados por uma matriz heterosexual. Esse fundamento, construindo toda uma arquitetura em torno do familialismo, do modelo edipiano papai-mamãe, da reprodução, da intimidade e da chamada infância, seria garantidor da manutenção e progresso do Estado soberano, produtivo, coeso e monocultural. A heteronormatividade - assim caracterizada como forma de governo - e seu pendor para o confinamento produzem cada aspecto da organização da vida social, fazendo-se presente no Estado, na lei, na política, na religião, na medicina, no trabalho, no comércio, na arquitetura, na mídia, na educação, na família, no lar e na linguagem. Berlant e Warner (2005) chegam a dizer que "a heterossexualidade envolve tantas práticas que não são sexo que um mundo no qual essa aglomeração hegemônica [de práticas] não fosse dominante seria, no atual momento, inimaginável” (2005, p. 557). É por essa razão que seria vital estranhá-la e entendê-la como dispositivo avesso às misturas e hibridismos. Nos termos do vocabulário de Sampaio (2001), é preciso estremecer $\mathrm{D}^{2}$ e repensar seus efeitos.

Julgo - inspirada por Mignolo (2000) e Moita Lopes (2013), entre outros - que o pensamento de fronteira (border thinking) pode ser uma das formas de operar esse estremecimento e nos ajudar a compreender os mais diversos limites mantenedores de zonas de inclusão e exclusão. Aproximar-se das margens e apostar em uma série de deslocamentos pode vir a constituir, organizar e fundar uma nova episteme.

Outro bloco de questões:

- Por que seria necessário mover-se além das fronteiras?

- Por que precisaríamos de outra episteme?

- Por que a linguística aplicada deveria operar esses deslocamentos?

\section{Deslocar-se para além das fronteiras em linguística aplicada}

A linguística aplicada, como uma das áreas que se ocupa da linguagem, é marcada fortemente por uma visão modernista de língua (MOITA LOPES, 2013). Essa perspectiva, condensada no diagrama saussuriano (cf. Figura 7), vem sendo reproduzida e questionada por diferentes estudiosas / os da linguagem (BLOMMAERT, 2013; BRIGGS, 2007a; KRESS; van LEEUWEN, 1996; SILVA, 2011; entre outros). 
FIGURA 7 - Circuito da fala

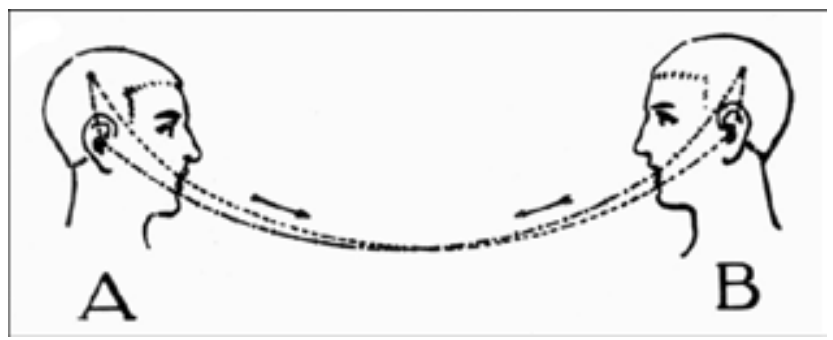

Fonte: Saussure (1978).

As escolhas semióticas que orientam a construção desse circuito seriam exemplos eloquentes da operação da lógica da dupla diferença $\left(\mathrm{D}^{2}\right)$, parecendo seguir à risca o "receituário" clássico para a produção de uma epistemologia das certezas: parâmetros como linearidade, objetividade, clareza, transparência, replicabilidade, controle e a radical separação entre linguagem, signo e mundo social nela condensados projetam a idealização do sujeito androcêntrico, heterossexual e racializado do qual falávamos, que usa a língua - sistemas de símbolos convencionais - para expressar seus pensamentos. O instrumental linguístico, concebido primordialmente como mediador entre o sujeito pensante e o mundo, não teria outra função que não a de intermediação epistêmica e de representação ou descrição de objetos isto é, pensamentos, ideias, estado de coisas e o chamado "real". O processo seria, sobretudo, mental, desvinculado de corpos e seus pertencimentos geográficos, comunitários, identitários e sociopolíticos.

Esse legado referencialista, abstrato, desencarnado e imaterial, superaria as contingências, imprevisibilidades, acasos, desgastes e contratempos do mundo exterior, e, assim abrigado e protegido de possíveis "contaminações" ou "ruídos", garantiria a apreensão e transmissão acuradas da realidade.

A crítica à tradição representacional não é recente e no âmbito da filosofia da linguagem pode retroceder a Austin (1990) e a Wittgenstein (1999). Entretanto, como nos lembra Briggs (2007b, p. 321), essa tradição é infecciosa e, pela repetição, adquiriu a aparência de substância e imobilidade que o leva a perguntar (ecoando questionamento de Bruno Latour): "Como é possível que esse 'móvel imutável' possa ter viajado por todos os cantos, atravessado escalas, campos sociais, gêneros, instituições, países, e fronteiras raciais sem praticamente alterar seu significado?”. 
Em face desse questionamento, deslocar-se para além das fronteiras na linguística aplicada seria colocar o processo de constituição desses perímetros em xeque, explorar seus efeitos de sentido e suas consequências materiais em práticas concretas de interação envolvendo indivíduos de carne e osso, suas ações e corpos. Sob um olhar perscrutador, as práticas cotidianas escapam da captura da norma, pois vazam, deslizam, e transbordam. A temporalidade e espacialidade ordinárias estão sempre em devir, repetindo, mas também negociando ou reinventando formas de ocupar um certo espaço-tempo social. Os agenciamentos estão por aí, em trânsito na micropolítica, se movimentando capilarmente dentro da fixidez das normas, em diferentes gradações de velocidade. Detectar sua potência seria uma questão de foco investigativo.

Mediante essas ponderações, apresento o último bloco de questões:

- Como abordar o par repetição-transformação?

- A categoria língua continua potente e viável?

- Que imagens estão sendo convocadas para se repensar as fronteiras em LA?

\section{Por uma INdisciplinaridade radical}

Não gosto de palavra acostumada.

(Livro sobre nada, Manoel de Barros)

Vivemos em uma era de transformações muito rápidas, marcadas pela velocidade em aceleração crescente. O "trans", como indicador de movimento, seria sua marca, enfatizando as potências transdisciplinares ou INdisciplinares. A celeridade com que tudo - pessoas, produtos, ideias, discursos e signos - circula e se move exacerba processos de (des) reterritorialização, descentrando a ideia de fronteira. Esses trânsitos intensos vêm sendo aludidos pelo conceito de "superdiversidade" (VERTOTEC, 2007). Pensado inicialmente como metáfora pertinente às mudanças em escala global nos fluxos de migração e aos novos padrões sociais e demográficos, o conceito naturalmente começou a ser empregado para caracterizar: a) a intensificação do contato com a "alteridade"; b) o choque de repertórios discursivos e sistemas de conhecimento dele decorrente; e 
c) mutações comunicativas, agora não mais capturáveis pelas categorias modernistas habituais como falante/ouvinte, competência, comunidade, língua etc.

O panorama superdiverso e seus desdobramentos nas práticas discursivo-textuais são assim qualificados por Marco Jacquemet (2005, p. 257):

Há mutações comunicativas resultantes da interseção entre pessoas móveis e textos móveis. Tecnologias sofisticadas de rápido deslocamento humano e comunicação global estão mudando o ambiente comunicativo na Modernidade recente [...] a experiência de globalização cultural e a desordem sociolinguística implicadas nessas transformações [...] demandam que consideremos as qualidades reconfiguradoras (recombinant qualities) de misturas linguísticas, hibridização e crioulização [...] As práticas comunicativas contemporâneas são baseadas em interações multilíngues (a maior parte das vezes envolvendo interlocutores des/ reterritorializados) realizadas através da mídia local e eletrônica.

É verdade que esses processos ganham visibilidade e concretude no mundo virtual, como pontua o autor, mas o que os distinguiria não seriam propriamente a mobilidade, o contato ou a mestiçagem. Esses aspectos sempre fizeram parte de nossa experiência textual: signos, discursos e textos só existem circulando; se referindo e se amalgamando a outros; forjando ambientes interacionais e construindo relações sociais. Esses processos cumprem itinerários imprevisíveis e vulneráveis, porque são atravessados de tensões, assimetrias e disputas pelo significado (como sinalizam os exemplos focalizados anteriormente). A novidade estaria no grau escalar da circulação e, como consequência, no incremento exponencial da zona de contato, da superfície de atrito, da diversidade de trajetórias (penso aqui nos fenômenos virais na internet) e das misturas, sobretudo das chamadas línguas nacionais. Estas últimas são rótulos que já não definem o que os interactantes fazem contemporaneamente em intercâmbios on-line e off-line e, por isso, vão instigando a criação de novos termos que possam qualificá-las. Jacquemet (2005), por exemplo, utiliza "práticas trans-idiomáticas"; Blommaert (2005) privilegia o conceito de "repertórios de recursos semióticos" e Canagarajah (2014) adota a expressão "práticas translíngues".

$\mathrm{Na}$ verdade, o mundo digital potencializa processos que sempre estiveram em curso; nele, as quatro lógicas em operação orientam a produção de sentidos. Talvez, devido ao aumento da fricção textual na web, $\mathrm{D}^{2}$ tenda a concentrar-se na repetição de binarismos e no trabalho de demarcação de 
divisas; trabalho muito mais árduo agora. A violência simbólica e a profusão de estereótipos e clichês presentes nessas ações esbarram na proliferação de contradiscursos (cf. FABRÍCIO 2015a, 2015b), de forma que a precariedade de $\mathrm{D}^{2}$, isto é, das formas hegemônicas em geral, vai sendo posta à prova, desgastando sua base no próprio movimento de repetição. A possibilidade de mudança estaria, então, na exploração desse equilíbrio instável.

Não creio que possamos criar inteligibilidade sobre esse dinamismo entre persistência e inovação com abordagens, teorizações, conceitos, imagens e nomenclatura vinculados a uma episteme modernista. Ela é demasiadamente estática e enrijecida.

Vejo na visão de linguagem performativa austiniana um caminho para se contrapor à tradição representacional, sobretudo sua releitura por Butler (1997) e Derrida (2013). Construtos como performatividade, citabilidade, iterabilidade, reconhecimento e vulnerabilidade fornecem uma bússola para a exploração de repetições-transformações e de uma epistemologia que eleja como objeto a precariedade, a imprecisão, o provisório e a mutabilidade. Para isso, temos que deslocar o foco de observação de $\mathrm{D}^{2}$, o campo das durabilidades, para D, o eixo do movimento. Esse eixo estaria nas margens, na região da indiferença e do indeterminado, não rendida à captura pela norma. Abordá-las não é uma simples questão de "ativismo" ou "bandeira ideológica" - clichês corriqueiros e desmerecedores de trabalhos em LA que focalizam as relações entre práticas semióticas, produção de gênero, sexualidade, raça, etnia e suas interseccionalidades. Se não conseguirmos provocar algum nível de descentramento na seara de $\mathrm{D}^{2}$, uma pirâmide hiperdialética móvel não poderá se insinuar, pois a base modernista-heterocapitalista permanecerá inerte e autocontida.

Esse esforço descentralizador também envolve revisitar e reinventar procedimentos metodológicos, a conexão entre sujeito e objeto de pesquisa, e a relação com o processo de produção de conhecimento. É preciso, então, emaranhar-se e afetar-se com e pelo objeto em construção, promovendo a cópula - como sugere Job (2010) - entre diferentes saberes e jogos de pensamento. A meu ver seria esse gesto que conferiria algum grau de complexidade à nossas pesquisas em LA.

Uma metáfora me ocorre como companhia na viagem proposta em direção ao pensamento hiperdialético e a uma INdisciplinaridade radical. 
FIGURA 8 - Faixa de Moebius em movimento

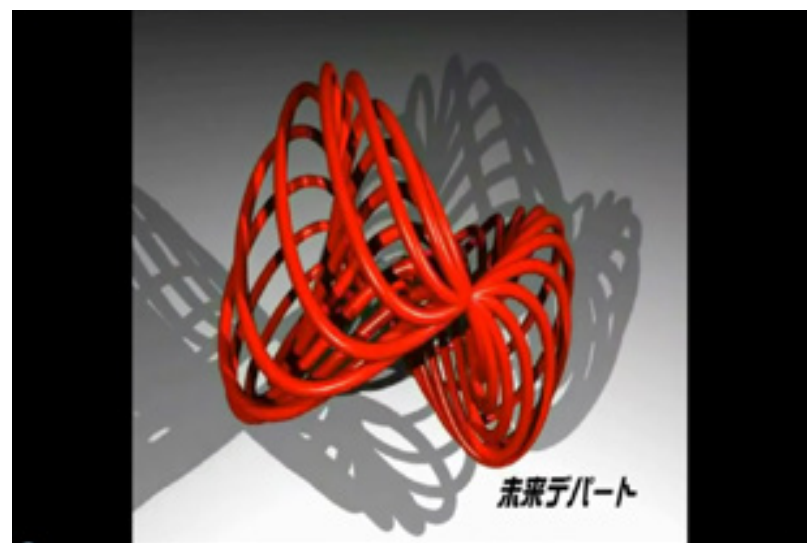

Fonte: Miraidep (2006)

A imagem materializa visualmente a ideia de trânsito que podemos imprimir à estrutura lógica do esquema de Sampaio (2001), na batalha contra $\mathrm{D}^{2}$. Entretanto, gostaria de terminar com as sugestões singelas, porém grandes em significância, de Manoel de Barros (2013), acerca de possíveis antídotos contra as fronteiras modernistas e os clichês: "Despraticar as normas", "Desaprender 8 horas por dia ensina os princípios [...] Desinventar objetos [...] usar palavras que ainda não tenham idioma [...] repetir repetir - até ficar diferente."

\section{Agradecimentos}

Ao CNPq, pela bolsa de produtividade em pesquisa ( $\left.n^{\circ} 307157 / 2013-0\right)$ que possibilitou a produção deste trabalho, bem como a Maria Celita Cardoso Beranger e Rodrigo Borba, pela leitura crítica da primeira versão do texto.

\section{Referências}

APPADURAI, A. Modernity at large: cultural dimensions of globalization. Minneapolis: University of Minnesota Press, 1996.

AUSTIN, J. L. Quando dizeré é faz̧er: palavras e ação. Tradução de Danilo Marcondes de Souza Filho. Porto Alegre: Artes Médicas, 1990.

BARROS, M. Manuel de Barros: poesia completa. São Paulo: LeYa, 2013.

BAUMAN, Z. Identidade. Tradução de Carlos Alberto Medeiros. Rio de Janeiro: Zahar, 2005. 
BAUMAN, R.; BRIGGS, C. L. Voices of modernity: language ideologies and the politics of inequality. Cambridge: Cambridge University Press, 2003. DOI: https:// doi.org/10.1017/CBO9780511486647

BERLANT, L.; WARNER, M. Sex in public. In: WARNER, M. Publics and counterpublics. New York: Zone Books, 2005. p. 187-208.

BHABHA, H. K. O local da cultura. Tradução de Myriam Ávila, Eliana Lourenço de Lima Reis e Gláucia Renate Gonçalves. Belo Horizonte: UFMG, 1998.

BLOMMAERT, J. Ethnography, superdiversity, and linguistic landscapes: chronicles of complexity. Bristol: Multilingual Matters, 2013.

BLOMMAERT, J. Discourse. Cambridge: Cambridge University Press, 2005. DOI: https://doi.org/10.1017/CBO9780511610295

BRIGGS, C. Anthropology, interviewing, and communicability in contemporary society. Current Anthropology, Chicago, v. 48, n. 4, p. 551-580, 2007a. DOI: https:/ / doi.org/10.1086/518300

BRIGGS, C. Mediating infanticide: theorizing relations between narrative and violence. Cultural Anthropology, Arlington County, v. 22, n. 3, p. 315-356, $2007 \mathrm{~b}$.

BUTLER, J. Gender trouble: feminism and the subversion of identity. New York: Routledge, 1990.

BUTLER, J. Excitable Speech: a politics of the performative. New York: Routledge, 1997.

CANAGARAJAH, S. Translingual practice: global Englishes and cosmopolitan relations. New York: Routledge, 2014.

DELEUZE, G. Diferença e repetição. Tradução de Luiz Orlandi e Roberto Machado. São Paulo: Graal, 2009.

DERRIDA, J. Gramatologia. 2. ed. São Paulo: Perspectiva, 2013.

FABRÍCIO, B. F. Policing the borderland in a digital Lusophone territory: the pragmatics of entextualization. In: MOITA LOPES, L. P. (Ed.). Global Portuguese: linguistic ideologies in late modernity. New York: Routledge, 2015a.

FABRÍCIO, B. F. Infectious repetition-differentiation in an online debate on sexualities: textual friction, scale shifts and resemiotization potential. Working Papers in Urban Language \& Literacies. Paper 167, London, 2015b. Disponível em: < https:/ / goo.gl/x6hHMz>. Acesso em: 5 jul. 2016.

FOUCAULT, M. História da sexualidade I: a vontade de saber. Tradução de Maria Thereza da Costa Albuquerque e J. A. Guilhon Albuquerque. Rio de Janeiro: Graal, 1988. 
FOUCAULT, M. Vigiar e punir: nascimento da prisão. Tradução de Raquel Ramalhete. Petrópolis: Vozes, 1996.

HALL, S. A identidade cultural na pós-modernidade. Tradução de Tomaz Tadeu da Silva e Guacira Lopes Louro. Rio de Janeiro: DP\&A, 1992.

JACQUEMET, M. Transidiomatic practices: language and power in the age of globalization. Language \& Communication, San Francisco, v. 25, p. 257-277, 2005. DOI: https://doi.org/10.1016/j.langcom.2005.05.001

JOB, N. Confluências entre magia, filosofia, ciência e arte: a ontologia onírica. Rio de Janeiro: Cassará, 2013a.

JOB, N. Manifesto Transaberes. Cosmos e Consciência, Rio de Janeiro, 1 fev. 2013b. Disponível em: < https://goo.gl/pDYFZQ>. Acesso em: 27 jan. 2015.

JOB, N. Um milhão de platôs: por uma transdisciplinaridade radical. Cosmos e Consciência, Rio de Janeiro, 6 mar. 2010. Disponível em: < https://goo.gl/wo2bcL> Acesso em: 5 jul. 2015.

KRESS, G.; VAN LEEUWEN, T. Reading images: the grammar of visual design. London: Routledge, 1996.

KROSKRITY, P. (Ed.). Regimes of language: ideologies, polities and identities. Santa Fe: School of American Research Press, 2000.

MAKONI, S.; PENNYCOOK, A. (Ed.). Disinventing and reconstituting languages. Clevedon: Multilingual Matters, 2006.

MIRAIDEP. 4d animation. YouTube. 2006. Disponível em: <https://goo.gl/ LocN7C> Acesso em: 12 jan. 2015.

MIGNOLO, W. D. Local histories/global designs: coloniality, subaltern knowledges, and border thinking. Princeton: Princeton University Press, 2000.

MOITA LOPES, L. P. (Org.). Por uma linguística aplicada indisciplinar. São Paulo: Parábola, 2006.

MOITA LOPES, L. P. Identidades fragmentadas: a construção discursiva de raça, gênero e sexualidade em sala de aula. Campinas: Mercado de Letras, 2002.

MOITA LOPES, L. P. (Org.). O português no século XXI: cenário geopolítico e sociolinguístico. São Paulo: Parábola, 2013.

MOITA LOPES, L. P. (Org.). Global Portuguese: linguistic ideologies in late modernity. New York: Routledge, 2015.

MOITA LOPES, L. P.; BASTOS, L. C. (Org.). Identidades: recortes multi e interdisciplinares. Campinas: Mercado de Letras, 2002.

MOITA LOPES, L. P.; BASTOS, L. C. (Org.). Para além da identidade: fluxos, movimentos e trânsitos. Belo Horizonte: UFMG, 2010. 
PAIVA, V. L. M. O.; NASCIMENTO, M. (Org.). Sistemas adaptativos complexos: lingua(gem) e aprendizagem. Belo Horizonte: UFMG, 2009.

PRATT, M. L. Linguistic utopias. In: FABB, N. et al. (Ed.). The linguistics of writing: arguments between language and literature. Manchester: Manchester University Press, 1987. p. 48-66.

PRECIADO, B. Manifesto contrassexual: práticas subversivas de identidade sexual. Tradução de Maria Paula Gurgel Ribeiro. São Paulo: N-1 Edições, 2014.

SADE, L. A. Fractals and fragmented identities in language acquisition. In: GONÇALVES, G. R. et al. (Org.). New challenges in language and literature. Belo Horizonte: UFMG, 2009. p. 109-127.

SAMPAIO, L. S. C. A lógica da diferença. Rio de Janeiro: Eduerj, 2001.

SAUSSURE, F. Curso de linguística geral. Tradução de Antônio Chelini, José Paulo Paes e Isidoro Blikstein. São Paulo: Cultrix, 1978.

SCHIEFFELIN, B.; WOOLARD, K.; KROSKRITY, P. (Ed.). Language ideologies: practice and theory. New York: Oxford University Press, 1998.

SIGNORINI, I. (Org.). Lingua(gem) e identidade: elementos para uma discussão no campo aplicado. Campinas: Mercado de Letras, 1998.

SIGNORINI, I.; CAVALCANTI, M. (Org.). Linguística aplicada e transdisciplinaridade: questões e perspectivas. Campinas: Mercado de Letras, 1998.

SILVA, D. N. A representação entre a mediação e a violência simbólica. In: CARMO, C. M. (Org.). Textos e práticas de representaşão. Curitiba: Honoris Causa, 2011. p. 121-145.

SILVA, F.; RAJAGOPALAN, K. (Org.). A linguística que nos faz falhar: investigação crítica. São Paulo: Parábola, 2004.

VERTOTEC, S. Super-diversity and its implications. Ethnic and Racial Studies, London, v. 30, n. 6, p. 1024-1054, 2007. DOI: https://doi.org/10.1080/01419870701599465 WITTGENSTEIN, L. Investigações filosóficas. Tradução de José Carlos Bruni. São Paulo: Nova Cultural, 1999. 
